\title{
Past Experience of Uncertainty Affects Risk Aversion*
}

\author{
Friederike Mengel ${ }^{+}$ \\ University of Essex \\ and Maastricht University
}

\author{
Elias Tsakas $\ddagger$ \\ Maastricht University
}

\section{Alexander Vostroknutov $§$}

Maastricht University

January 2015

\begin{abstract}
In an experiment with more than 500 participants we study how past experience of uncertainty (imperfect knowledge of the state space) affects risk preferences. Participants in our experiment choose between a sure outcome and a lottery in 32 periods. All treatments are exactly identical in periods 17 to 32 but differ in periods 1 to 16 . In the early periods of the Risk Treatment there is perfect information about the lottery; in the Ambiguity Treatment participants perfectly know the outcome space but not the associated probabilities; in the Unawareness Treatment participants have imperfect knowledge about both outcomes and probabilities. We observe strong treatment effects on behavior in periods 17 to 32. In particular, participants who have been exposed to an environment with very imperfect knowledge of the state space subsequently choose lotteries with high (low) variance less (more) often compared to other participants. Estimating individual risk attitudes from choices in periods 17 to 32 we find that the distribution of risk attitude parameters across our treatments can be ranked in terms of first order stochastic dominance. Our results show how exposure to environments with different degrees of uncertainty can affect individuals' subsequent risk-taking behavior.
\end{abstract}

JEL classification: D80, D81, C91

Keywords: risk preferences, ambiguity, unawareness, experiments.

\footnotetext{
*We would like to thank Douglas Bernheim, Elena Cettolin, David Cooper, Vincent Crawford, Matt Embrey, Jayant Ganguli, David Huffman, David Laibson, Dan Levin, Ulrike Malmendier, Ronald Peeters, Arno Riedl, David Schmeidler, Kaj Thomsson, Huanxin Yang, two anonymous reviewers as well as seminar participants at Göteborg University, Maastricht University, Ohio State University, RUD 2011, SAET 2011, EEA-ESEM 2011 and SITE Psychology and Economics Workshop 2011 for invaluable comments and help. All mistakes are ours. Friederike Mengel thanks the European Union (grant PERG08-GA-2010-277026) for financial support. A previous version was circulated under the title "Decision-making with imperfect knowledge of the state space".

${ }^{\dagger}$ Department of Economics, University of Essex, Wivenhoe Park, Colchester CO4 3SQ, United Kingdom, e-mail: fr.mengel@gmail.com

$\ddagger$ Department of Economics (AE1), Maastricht University, PO Box 616, 6200 MD Maastricht, The Netherlands

$\S$ Department of Economics (AE1), Maastricht University, PO Box 616, 6200 MD Maastricht, The Netherlands
} 


\section{Introduction}

\subsection{Motivation and Outline}

Research in Economics has suggested that exposure to uncertain environments can influence economic decision making and future perception of risk. Malmendier and Nagel (2011), for example, show that periods of macroeconomic uncertainty (like the Great Depression) decreases people's willingness to take financial risks in the long run. Nishiyama (2006) demonstrates that the Asian crisis of 1997 seems to have led to a persistent increase in US banks' risk aversion. And Callen et al. (2014) and Kim and Lee (2014) show that elicited risk aversion increases after exposure to violence or war.

One difficulty with empirical field studies is to isolate and measure the effect of exposure to such uncertain environments on risk aversion. Using field data, it is hard to measure the degree of uncertainty in an environment. It is also difficult to identify whether it is the fact that agents experience particularly good or bad outcomes or whether it is the exposure to uncertain environments that shape future risk aversion. In addition, probabilities of different events are rarely observed in the field, and therefore what looks like an increase in risk aversion may simply be (Bayesian) updating of consumers', banks' or other market participants' priors. Conducting a laboratory experiment can help to circumvent all these problems.

In the literature on decision making under uncertainty there are three standard "types" of uncertainty, which can be ordered with respect to the (increasing) degree of uncertainty that they induce. In particular, in a risky environment a decision maker knows all possible outcomes, as well as the associated probabilities. In an ambiguous environment the decision maker is typically assumed to know all possible outcomes but not necessarily the corresponding probabilities with which they occur (Ellsberg, 1961; Maccheroni et al., 2006). Such "immeasurable" risk is also often referred to as Knightian uncertainty (Knight, 1921). Finally, in addition to not knowing the objective probabilities associated with each outcome the decision maker might be unaware of some possibilities entirely.

In this paper we study how the degree of such imperfect knowledge of the state space affects risk attitudes in subsequent unrelated choices under uncertainty with perfect knowledge of the state space. Over 500 people participated in our computer lab experiment. Participants are first given a sequence of choices between a fixed lottery and varying sure monetary outcomes (first task). There are three treatments that differ in the amount of information available about the lottery. In the Risk treatment participants are informed about all outcomes of the lottery as well as their probabilities. In the Ambiguity treatment the participants are informed only about the possible outcomes, but not about the associated probabilities. In the Unawareness treatment 
participants are only informed about some possible outcomes and no information is given about probabilities. Upon choosing the lottery they can become aware of additional outcomes if they are realized. In each treatment it is clearly explained to participants which amount of information they do or do not have. This also means that in the Unawareness treatment they are "aware of their own unawareness." ${ }^{1}$ After the first task participants in all three treatments are given another sequence of choices between different lotteries and sure outcomes with all information available (second task).

Note that it is possible that a decision-maker in our ambiguity treatment acts as a subjective expected utility (SEU) maximizer. Equally it is possible that a decision maker in the Unawareness treatment deems "all" outcomes possible and then chooses as if the environment was one of ambiguity. ${ }^{2}$ Since the cardinality of the set of "all possible outcomes" is very large, it is hardly conceivable that the decision maker would actually do this. But it is a theoretical possibility. Hence, it is important to notice that in this experiment we are interested in how experiencing environments with different degrees of uncertainty about the state space shapes future risk preferences. Unlike much of the existing literature, we are not primarily interested in how individuals make decisions in these three environments or whether they are ambiguity averse. ${ }^{3}$ Therefore, in what follows, we will distinguish the environments (Risk, Ambiguity, Unawareness) by the information we provide without any claim as to whether behavior in the three treatments corresponds to any existing models of decision-making in these environments.

Our main finding is that participants who have been exposed to an environment with imperfect knowledge of the state space subsequently become more risk averse in standard decision making under risk than participants who had full information about the state space. In particular, participants in the Unawareness treatment choose high variance lotteries significantly less often on average than participants in the Ambiguity treatment who, in turn, choose the same lotteries significantly less often than participants in the Risk treatment. We estimate individual risk attitudes from choices in the second task and find that the distribution of risk attitude parameters across our treatments can be ranked in terms of first order stochastic dominance (FOSD). We also conduct this analysis separately for early and late periods within the second task to see if the effect dies out over time. We find that, if at all, the effect is stronger in later periods.

We conjecture that these spillovers are due to the fact that participants in the treat-

\footnotetext{
${ }^{1}$ See the literature surveyed below.

${ }^{2}$ Distinguishing zero probability events from unawareness is a topic which has attracted attention in theoretical research. See, for example, Feinberg (2009) for discussion.

${ }^{3}$ See for example Ellsberg (1961), Halevy (2007), Gollier (2011) among many others.
} 
ments with less information about the state space become more sensitive to the variance or risk associated with a lottery. Additional treatments help us to distinguish between different explanations of our main result. We first ask whether it is exposure to extreme realizations (i.e. negative vs. positive outcomes) or the uncertainty of the environment per se that drives our result. We address this question in an additional treatment where we replace "negative surprises" with "positive surprises" and find that it is the mere presence of surprises and not their valence that triggers the results. Another possible hypothesis is that risk attitudes are affected by perceived risk in the first phase of the Ambiguity and Unawareness treatments rather than imperfect knowledge of the state space. To address this possibility we conduct an additional treatment, which coincides with the Risk treatment, but where the lottery has higher variance. We find that a $300 \%$ increase in risk (measured by the variance of the lottery) produces the same effect as the Risk treatment. Hence, if there is an equivalent increase in risk that produces the same effect as the Ambiguity and Unawareness treatments, this increase has to be (much) more than $300 \%$. We also show that there are no reasonable priors in the Ambiguity and Unawareness treatments that could possibly produce such an increase in perceived risk. All this suggests that it is information about the state space per se that matters, rather than inferred perceptions of risk.

Our results should be of interest to any social scientist interested in how experiencing environments of different degrees of uncertainty shape risk preferences. Different political systems, media and education systems all create such different environments. To the extent that our results transfer to such settings they are potentially actionable by both marketers and policy makers in product design and policy interventions.

\subsection{Related Literature}

Previous research has used field data to demonstrate that risk-taking behavior is affected by periods of macroeconomic uncertainty (Malmendier and Nagel, 2011), financial crises (Nishiyama, 2006) or exposure to violence and war (Callen et al., 2014; Kim and Lee, 2014). However, it is difficult to establish in field studies whether such effects are due to an increase in risk aversion or to updated priors or other reasons. For example, Giuliano and Spilimbergo (2009) show that people growing up in a recession have different socio-economic beliefs than people growing up during a boom. Osili and Paulson (2009) show that macroeconomic shocks affect investor confidence. ${ }^{4}$ Furthermore, it is difficult to pin down in field studies what exactly

\footnotetext{
${ }^{4}$ Similarly, Malmendier and Nagel (2011) show that subjective expectations about future inflation are shaped by people's lifetime experience of inflation.
} 
drives this effect. For example, one could ask whether it is imperfect knowledge of the state space or exposure to good vs. bad outcomes that drives such effects. Our study avoids many of these problems and allows us to establish a clear link between imperfect knowledge of the state space and risk aversion.

Our research also contributes to the large literature that asks whether risk preferences are malleable. Barseghyan et al. (2011) use insurance data to show that estimated risk aversion parameters are not constant across different contexts (types of insurance). In a similar study Einav et al. (2011) find that there is a domain-general component of risk preferences, but that the common element is weak if domains are "very different." Dohmen et al. (2011), by contrast, detect some stability of risk preferences. Other studies of the stability of risk preferences across different domains include Andersen et al. (2008) or Barsky et al. (1997) among others. We go one step beyond this literature by asking not only whether risk preferences are stable, but also by identifying one possible source of variation in risk attitudes over time. ${ }^{5}$

We also contribute to the unawareness literature by proposing an experimental design to study (awareness of) unawareness. While we are not primarily interested in how people make decisions being aware of unawareness, our design can help to inspire experiments studying such questions. Unawareness has recently attracted quite a lot of attention among game theorists as a special case of reasoning in the absence of introspective capacities. ${ }^{6}$ The first major contributions in this literature show that accommodating a notion of unawareness which satisfies some reasonable axioms is impossible both in a standard state space model (Dekel et al., 1998) and in a syntactic model (Modica and Rustichini, 1994). The solution that was proposed in order to overcome the technical difficulties emerging from these results was to make reasoning an awareness-dependent process (Fagin and Halpern, 1988; Modica and Rustichini, 1999; Heifetz et al., 2006, 2008; Li, 2009). All the early models share the common feature that agents are unaware of their own unawareness (AUintrospection). Halpern and Rêgo (2009) have recently extended this framework to capture states of mind in which agents are aware of the possibility that they may be unaware of some fact. This is the case that corresponds to our experiment, since-as mentioned before-participants in our experiment are aware of the fact that they may be unaware of some outcomes.

The paper is organized as follows. Section 2 gives the details of the experimental

\footnotetext{
${ }^{5}$ In a different strand of literature it has been demonstrated that individual decisions are affected by whether a choice situation displays only risk or whether it is ambiguous (Ellsberg, 1961; Halevy, 2007; Gollier, 2011, among many others). Other authors have tried to establish correlations between risk aversion and ambiguity aversion. These results are quite different from our experiment in that we do not compare behavior in risky/ambigous environments but rather investigate how having been exposed to such an environment affects risk attitudes in subsequent unrelated choices.
}

${ }^{6}$ See for instance Feinberg (2009), Halpern and Rêgo (2008), Gossner and Tsakas (2010, 2012). 
design. Section 3 describes the statistical tools and the mean-variance utility model we estimate. In section 4 we present the main results. Section 5 discusses additional treatments and robustness checks. Section 6 concludes. An appendix contains instructions and further details of the experiment.

\section{Experimental Design}

In our experiment, participants are presented with 32 consecutive choices between lotteries and sure outcomes. There are 6 treatments in total. The three main treatments are called Unawareness, Ambiguity, and Risk. These treatments differ only in the amount of information provided to the participants about the lottery during the first 16 choices. Choices 17 to 32 are exactly the same across all treatments.

In periods 1 to 16 participants choose between a fixed lottery and varying sure outcomes. If they choose the lottery, the realized outcome is shown to them. If a participant chooses sure outcome the lottery realization is not displayed. The lottery in periods 1 to 16 is presented in Table 1 . Notice that apart from the monetary outcomes the lottery also has an outcome called Twix. A participant who chose the lottery and received the Twix outcome was given a real Twix chocolate bar at the end of the experiment. The idea behind the introduction of non-monetary outcome is to enlarge the space of outcomes that participants might consider. The sure outcomes in the first 16 choices varied from 5.4 Euro to 8.4 Euro with a 0.2 Euro interval and occurred in the same random order in all treatments. ${ }^{7}$

\begin{tabular}{llllllll}
\hline Outcomes (Euro) & & & & & & & \\
& -20 & -1 & Twix & 6 & 8 & 10 & 14 \\
& 0.001 & 0.05 & 0.05 & 0.2 & 0.25 & 0.379 & 0.07 \\
Probabilities & & & & & & & \\
\hline
\end{tabular}

Table 1: The lottery participants faced in periods 1 to 16.

The treatments differ in the amount of information participants have about the lottery in Table 1. In the Risk treatment participants observe all outcomes and all probabilities as shown in Table 1. In the Ambiguity treatment participants are shown all outcomes but not the associated probabilities. ${ }^{8}$ In the Unawareness treatment participants see no probabilities and only some outcomes. In particular, from the first period on participants observe the possible outcomes $6,8,10$ and 14; starting from

\footnotetext{
${ }^{7}$ The sequence of sure outcomes was the same for all participants: $7,7.4,8.2,5.4,6,8,5.8,6.6,7.2,7.6$, $8.4,7.8,6.4,6.8,6.2,5.6$. The lottery realizations (when lottery was chosen) were generated randomly for each participant.

${ }^{8}$ If the reader wants to think in terms of a state space and subjective probabilities, here is one example of such a state space. Think of an urn with 1000 balls. Some of these balls have written -20 on them, some Twix, some 10 etc. The decision maker does not know the number of balls of each kind. However, s/he knows all the possible numbers (labels of balls) that are allowed.
} 
period 6, irrespective of their choices, they are also shown the possible outcome -1 ; starting from period 11 they are shown Twix; and in period 16 they see outcome -20 . If a participant chooses the lottery and an outcome is realized that she was previously unaware of (that she was not shown previously) she is informed about this realization and the outcome is displayed in all subsequent periods. If a participant does not choose the lottery she does not learn its realization. The reason that participants were initially only informed about positive outcomes is that negative outcomes are unusual in experiments and hence would generate more surprise (becoming aware of unawareness). The order of revelation -1 , Twix, -20 was chosen to maximize "surprise." In all treatments participants are informed about these details in the Instructions, i.e. they know in the Ambiguity and Risk treatments that they know all outcomes and in the Unawareness treatment they are aware of the fact that they do not know all outcomes. ${ }^{9}$ Figures 1 .abc illustrate how the choices were presented to the participants.

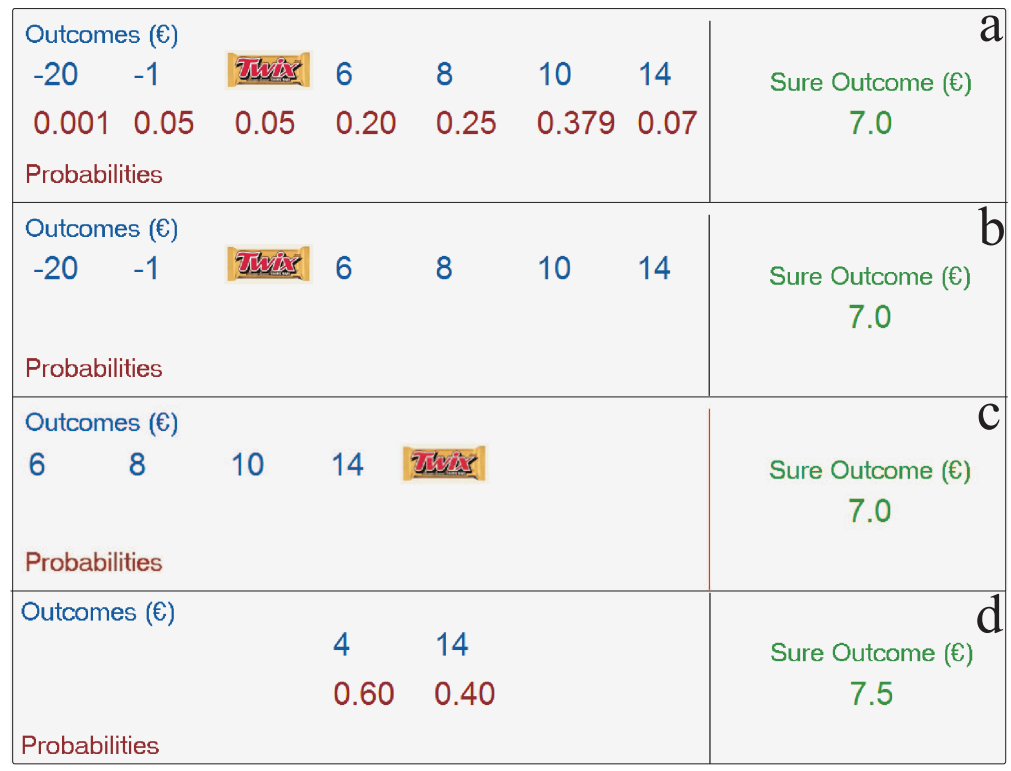

Figure 1: Screen shots of a typical choice in periods 1 to 16 in a) Risk treatment; b) Ambiguity treatment; c) Unawareness treatment: screen of a participant who received a Twix some time before Period 6. d) one typical choice from periods 17 to 32 (identical in all treatments).

In all treatments the choices in periods 17 to 32 are between different lotteries with 2 outcomes and different sure amounts. The participants observe the lottery realization if it was chosen. They do not observe lottery realization if the sure outcome was chosen. These choices are the same across all treatments. Participants observe both outcomes and associated probabilities in all periods (see Figure 1.d). Hence, all treatments are exactly identical in periods 17 to 32 . The outcomes of the lotteries vary

\footnotetext{
${ }^{9}$ We ran the treatments in the order Unawareness, Ambiguity, Risk to avoid communication among participants regarding the information provided in different treatments.
} 
between 2 Euro and 20 Euro. The probabilities are chosen such that the expected values of all lotteries are close to 8 Euro (in the interval between 7.94 and 8.05 Euro). The sure outcomes vary between 6 and 8 Euro with a 0.5 Euro interval. In all treatments all participants face the same sequence of lotteries. However, they observed different sequences of sure outcomes. In particular, the participants were randomly assigned to one of four cohorts. Each cohort received the same random draw as a sequence of sure outcomes in all treatments. ${ }^{10}$ All participants are explicitly informed that there are no other outcomes than those shown on the screen. They could also infer this from the fact that probabilities add up to one.

At this point it is important to remember that we are interested mainly in behavior in periods 17 to 32 which are identical across treatments. We are not interested, for example, in eliciting ambiguity attitudes, which would clearly not be possible with our design, since we do not know which priors participants have about the lottery in periods 1 to 16 . We will return to this question in Section 5.

In addition to the Risk, Ambiguity and Unawareness treatments we ran three more treatments: 1) A control treatment in which subjects faced only the lotteries from periods 17 to 32 (Control); 2) A treatment which is identical to the Unawareness treatment except that the payoff -20 was replaced by +20 (Unawareness-POS); 3) A treatment which coincided with the Risk treatment except that the outcomes of the lottery in periods 1 to 16 were associated with different probabilities such that variance was increased (Risk-high). We discuss these additional treatments in Sections 5.2, 5.3 and 5.4. We did not run any other treatments than the 6 treatments described, nor did we run any pilot sessions. ${ }^{11}$

At the end of the experiment the participants were paid for one randomly chosen period in addition to a 4 Euro show-up fee. ${ }^{12} 508$ participants took part in our experiment. 104 participated in the Risk treatment; 100 participants in the Ambiguity treatment; 106 participants in the Unawareness treatment; 32 participants in the Control treatment; 85 participants in Unawareness-POS treatment; and 81 participants in Risk with high variance treatment. Each participant is one independent observation. The minimum earnings in the experiment were 3 Euros and the maximum 23 Euros. The experiment lasted between 30-50 minutes. All experiments were run with $z$-Tree (Fischbacher, 2007) at Maastricht University in June-September 2010 (Unawareness, Ambiguity, Risk and Control treatments) and May 2011 (Unawareness-POS and Riskhigh).

\footnotetext{
${ }^{10}$ See Section A in the Supplementary Material (http://www.vostroknutov.com/pdfs/awarexp04supp.pdf) for more details.

${ }^{11}$ We disregard the data from one session of the Unawareness treatment where there was a substantial programming error.

${ }^{12}$ Starmer and Sugden (1991) study the validity of the random lottery incentive system and find that participants treat every choice situation as isolated.
} 


\section{Methods}

In order to estimate risk attitudes we use a mean-variance utility model (Markowitz, 1952). The utility derived from a lottery is assumed to be a weighted sum of its expected value and standard deviation. The (positive) coefficient on the expected value reflects the desire for higher monetary outcome and the negative coefficient on standard deviation reflects risk aversion. The mean-variance model is widely used to model decisions in finance and economics. ${ }^{13}$ Some neuroeconomic evidence (e.g. Preuschoff et al., 2006) even claims that mean-variance utility is encoded in the striatal regions of the brain.

Consider a lottery $\ell=\left(x_{1} \circ p_{1}, x_{2} \circ p_{2}, \ldots, x_{n} \circ p_{n}\right)$. We model utility as

$$
u(\ell)=K_{\theta}+\alpha_{\theta} \mu_{\ell}-\beta_{\theta} \sigma_{\ell}
$$

where $\alpha_{\theta}, \beta_{\theta}>0, K_{\theta}$ is a constant, $\mu_{\ell}$ is expected value, $\sigma_{\ell}$ is standard deviation and the subindex $\theta$ denotes the treatment (Risk, Ambiguity, Unawareness). ${ }^{14}$ For the degenerate lottery $(x)$ we have $u(x)=K_{\theta}+\alpha_{\theta} x$. We use a random utility model (see e.g. McFadden, 1976) which assumes that the probability of choosing the lottery $\ell$ over sure outcome $x$ is monotonic with respect to the difference of the utilities

$$
u(\ell)-u(x)=\alpha_{\theta}\left(\mu_{\ell}-x\right)-\beta_{\theta} \sigma_{\ell}
$$

To estimate $K_{\theta}, \alpha_{\theta}$ and $\beta_{\theta}$ we use random effects logit regressions. In what follows the independent variable $\left(\mu_{\ell t}-x_{t}\right)$ will be called dexp and $\sigma_{\ell t}$ will be called stdv, where $t$ indexes period. Table 2 summarizes the variables we use in the main regressions.

As an alternative to the mean-variance utility we could have estimated risk aversion coefficients from e.g. CRRA or similar utility models. In Section D of the Supplementary Material we also estimate individual CRRA coefficients and show that (a) our qualitative results in terms of treatment rankings are robust and (b) that the estimated CRRA coefficients and the estimated $\beta$ 's from the mean variance model are significantly correlated.

Another possibility would have been to elicit certainty equivalents using the BDM mechanism (Becker et al., 1964). While it has the advantage of being more direct, there are several reasons to prefer binary choices to the BDM mechanism. First, binary choices have the advantage of being simple and easy to understand. Second, while (under certain assumptions) the BDM mechanism is theoretically incentive compat-

\footnotetext{
${ }^{13}$ See Markowitz (1952), Levy and Markowitz (1979) or the textbook by Sharpe (2008) among many others.

${ }^{14}$ We use standard deviation instead of variance, because standard deviation is measured in the same units as expected value, which makes it easier to compare coefficients. Non-surprisingly our results are robust to using either standard deviation or variance.
} 


\begin{tabular}{ll}
\hline \hline Variable & Definition \\
\hline per & $\begin{array}{l}\text { period. Ranges from } 1 \text { to } 16 \text { for the first } 16 \text { periods and normalized } \\
\text { to } 1 \text { to } 16 \text { for the last } 16 \text { periods (first and last } 16 \text { periods are always } \\
\text { analyzed separately) }\end{array}$ \\
$\begin{array}{l}\text { choice } \\
\text { resptime }\end{array}$ & $\begin{array}{l}\text { response time in seconds } \\
\text { dumawar }\end{array}$ \\
amb & dummy Unawaren Ambiguity treatment \\
unawarpos & dummy Unawareness-POS treatment \\
riskhigh & dummy Risk-high treatment \\
control & dummy Control treatment \\
sure & value of sure outcome (x) in first 16 periods. Range $[5.4,8.4]$, mean \\
dexp & 6.9 \\
stdv & $\mu_{\ell}-x$. Range $[-0.06,2.04]$, mean 0.99, periods 17 to 32 \\
\hline
\end{tabular}

Table 2: Variables used in regressions.

ible, it has been shown to be empirically unreliable (see e.g. Cason and Plott, 2014). Third, the BDM mechanism is not always incentive compatible. For example, if preferences do not satisfy the axioms underlying expected utility theory (in particular, independence and reduction of compound lotteries), the BDM mechanism may not elicit preferences accurately. In fact "certainty equivalents" elicited under the BDM mechanism respect the preference ordering if and only if preferences satisfy the independence axiom (Karni and Safra, 1987).

\section{Main Result}

In this section we analyze treatment differences in periods 17 to 32 . As was mentioned above the choices that participants face in these periods are exactly identical in all three treatments. Therefore, any behavioral differences between treatments should be attributed to the experiences participants had in periods 1 to 16 . We start with some descriptive statistics. The median number of times the lottery is chosen by any participant is 10 (mean 9.63) in the Risk treatment, 9 in the Ambiguity treatment (mean 9.17) and 9 in the Unawareness treatment (mean 8.91). To understand how these differences relate to risk aversion and to be able to assess the statistical significance we now turn to regression analysis.

Table 3 shows the results of a random effects logit regression for choices in periods 17 to $32 .{ }^{15}$ Independent variables of interest are dexp - the difference between the expected value of the lottery and the sure outcome (ranging from -0.06 to 2.04

\footnotetext{
${ }^{15}$ See Table 2 for definitions of the independent variables and the Supplementary Material (http://www.vostroknutov.com/pdfs/awarexp04supp.pdf) for a description of all lotteries.
} 


\begin{tabular}{|c|c|c|c|c|c|c|}
\hline \multicolumn{7}{|c|}{$\begin{array}{c}\text { Pr(Lottery) } \\
\text { Risk, Ambiguity, Unawareness }\end{array}$} \\
\hline & $(1)$ & (2) & (3) & $(4)$ & (5) & (6) \\
\hline $\operatorname{dexp}$ & $\begin{array}{l}1.266^{* * *} \\
(0.107)\end{array}$ & $\begin{array}{l}1.265^{* * *} \\
(0.107)\end{array}$ & $\begin{array}{l}1.252^{* * *} \\
(0.106)\end{array}$ & $\begin{array}{l}1.212^{* * *} \\
(0.063)\end{array}$ & $\begin{array}{l}1.218^{* * *} \\
(0.105)\end{array}$ & $\begin{array}{l}1.180^{* * *} \\
(0.062)\end{array}$ \\
\hline stdv & $\begin{array}{c}-0.347^{* * *} \\
(0.061)\end{array}$ & $\begin{array}{c}-0.325^{* * *} \\
(0.038)\end{array}$ & $\begin{array}{c}-0.322^{* * *} \\
(0.038)\end{array}$ & $\begin{array}{c}-0.320^{* * *} \\
(0.037)\end{array}$ & $\begin{array}{c}-0.312^{* * *} \\
(0.037)\end{array}$ & $\begin{array}{c}-0.311^{* * *} \\
(0.037)\end{array}$ \\
\hline per & $\begin{array}{c}-0.069^{* *} \\
(0.032)\end{array}$ & $\begin{array}{c}-0.056^{* * *} \\
(0.014)\end{array}$ & $\begin{array}{c}-0.043^{* * *} \\
(0.008)\end{array}$ & $\begin{array}{c}-0.043^{* * *} \\
(0.008)\end{array}$ & & \\
\hline stdv per & $\begin{array}{l}0.003 \\
(0.007)\end{array}$ & & & & & \\
\hline unawar & $\begin{array}{l}0.861^{* *} \\
(0.385)\end{array}$ & $\begin{array}{l}0.859 * * \\
(0.384)\end{array}$ & $\begin{array}{l}1.093^{* * *} \\
(0.342)\end{array}$ & $\begin{array}{l}1.079 * * * \\
(0.328)\end{array}$ & $\begin{array}{l}1.073^{* * *} \\
(0.339)\end{array}$ & $\begin{array}{l}1.061^{* * *} \\
(0.324)\end{array}$ \\
\hline$a m b$ & $\begin{array}{l}0.513 \\
(0.387)\end{array}$ & $\begin{array}{l}0.513 \\
(0.387)\end{array}$ & $\begin{array}{l}0.629^{*} \\
(0.344)\end{array}$ & $\begin{array}{l}0.555^{*} \\
(0.328)\end{array}$ & $\begin{array}{l}0.621^{*} \\
(0.341)\end{array}$ & $\begin{array}{l}0.549^{*} \\
(0.325)\end{array}$ \\
\hline unawar.stdv & $\begin{array}{c}-0.260^{* * *} \\
(0.056)\end{array}$ & $\begin{array}{c}-0.260^{* * *} \\
(0.056)\end{array}$ & $\begin{array}{c}-0.267^{* * *} \\
(0.056)\end{array}$ & $\begin{array}{c}-0.267^{* * *} \\
(0.055)\end{array}$ & $\begin{array}{c}-0.264^{* * *} \\
(0.055)\end{array}$ & $\begin{array}{c}-0.263^{* * *} \\
(0.054)\end{array}$ \\
\hline$a m b \cdot s t d v$ & $\begin{array}{c}-0.149^{* * *} \\
(0.056)\end{array}$ & $\begin{array}{c}-0.149^{* * *} \\
(0.056)\end{array}$ & $\begin{array}{c}-0.152^{* * *} \\
(0.055)\end{array}$ & $\begin{array}{c}-0.158^{* * *} \\
(0.055)\end{array}$ & $\begin{array}{c}-0.151^{* * *} \\
(0.055)\end{array}$ & $\begin{array}{c}-0.156^{* * *} \\
(0.054)\end{array}$ \\
\hline unawar.dexp & $\begin{array}{r}-0.038 \\
(0.151)\end{array}$ & $\begin{array}{r}-0.038 \\
(0.151)\end{array}$ & $\begin{array}{r}-0.015 \\
(0.149)\end{array}$ & & $\begin{array}{r}-0.012 \\
(0.149)\end{array}$ & \\
\hline$a m b \cdot d \exp$ & $\begin{array}{r}-0.120 \\
(0.151)\end{array}$ & $\begin{array}{r}-0.120 \\
(0.151)\end{array}$ & $\begin{array}{r}-0.107 \\
(0.150)\end{array}$ & & $\begin{array}{r}-0.105 \\
(0.149)\end{array}$ & \\
\hline unawar·per & $\begin{array}{l}0.025 \\
(0.019)\end{array}$ & $\begin{array}{l}0.025 \\
(0.019)\end{array}$ & & & & \\
\hline amb.per & $\begin{array}{l}0.013 \\
(0.019)\end{array}$ & $\begin{array}{l}0.013 \\
(0.019)\end{array}$ & & & & \\
\hline const & $\begin{array}{l}1.385^{* * *} \\
(0.337)\end{array}$ & $\begin{array}{l}1.294^{* * *} \\
(0.269)\end{array}$ & $\begin{array}{l}1.178^{* * *} \\
(0.248)\end{array}$ & $\begin{array}{l}1.207^{* * *} \\
(0.241)\end{array}$ & $\begin{array}{l}0.795^{* * *} \\
(0.236)\end{array}$ & $\begin{array}{l}0.822^{* * *} \\
(0.228)\end{array}$ \\
\hline$N$ & 310 & 310 & 310 & 310 & 310 & 310 \\
\hline
\end{tabular}

Table 3: Random effects logit regression of choices between lotteries and sure outcomes in periods 17 to $32\left(^{*}-10 \%\right.$ significance; $\left.{ }^{* *}-5 \% ;{ }^{* *}-1 \%\right)$. The numbers in parentheses are standard errors. The six different columns contain different specifications of our main regression. The first 4 columns contain a period term and/or its interactions. 4960 observations, 310 independent.

with an average of 0.99$) ;{ }^{16} \mathrm{stdv}$ - the standard deviation of the lottery (ranging from 1.73 to 8.46 with an average of 4.54 ); per - the number of the period (normalized to range from 1 to 16); unawar and amb - the dummies corresponding to treatments Unawareness (unawar) and Ambiguity (amb) as well as interactions. As can be seen from columns (1-3) and (5) of Table 3 in all three treatments participants respond in the same way to dexp (the difference between the expected values of lotteries and sure outcomes). In particular, the coefficients on the interaction terms unawar-dexp and amb-dexp are relatively small and statistically insignificant. Participants also tend to choose lotteries less often over time (per is significant and negative), but again there are no statistically significant treatment differences (unawar·per and amb·per are insignificant). We included the variable per as well as interaction effects in regressions

\footnotetext{
${ }^{16}$ Note that only very few values of dexp are negative since the sure outcome typically is lower than the expected value of the lottery.
} 
(1-4) to ensure that our variables dexp and stdv do not pick up time effects. ${ }^{17}$ Regressions (5) and (6) show that our results are robust and quantitatively unchanged if we omit all period terms.

The most interesting effect is the sensitivity to the standard deviation of the lotteries across treatments. The sensitivity to standard deviation is lowest in the Risk treatment (stdv), higher in the Ambiguity treatment (stdv + amb.stdv), and highest in the Unawareness treatment (stdv + unawar.stdv). In the Ambiguity treatment the regression coefficient for the standard deviation of the lottery is -0.478 with standard error 0.041 and $p<0.0001$. In the Unawareness treatment it is -0.587 with standard error 0.041 and $p<0.0001$ (column 4). The difference of coefficients between Unawareness and Ambiguity treatments is -0.109 with standard error 0.057 and $p=0.054$ (unawar.stdv - amb.stdv).

To check for robustness we also estimated the model using individual fixed effects logit; a random effects OLS; and separate random effects logit regressions for each treatment (see Section B of the Supplementary Material). Under the fixed effects model the coefficients and significance levels in all five specifications in Table 3 are almost exactly the same. The OLS model has the same significance levels of all coefficients in all specifications and very similar marginal effects. The separate logit regressions are almost exactly the same as the main logit regression with dummies for treatments. Thus we conclude that all results are fully robust to these alternative estimations.

Taken together, these results imply that for lotteries with standard deviations close to zero participants choose the lottery with the highest probability in the Unawareness treatment, lower probability in the Ambiguity treatment and the lowest probability in the Risk treatment. However, for the lotteries with high standard deviation ( $\mathrm{stdv}>3.8$ approximately) the situation is reversed. Participants choose high standard deviation lotteries with the lowest probability in the Unawareness treatment, higher probability in the Ambiguity treatment and the highest probability in the Risk treatment. Interestingly, the critical level of $\sigma$ for which the ranking of treatments reverses coincides with the standard deviation of the lottery from periods 1 to 16 . This lends support to our conjecture that participants become more sensitive to the standard deviations of the lotteries in periods 17 to 32 if they have been previously exposed to an environment characterized by very imperfect knowledge of the state space.

Figure 2 plots the estimated probability with which a lottery was chosen in periods 17 to 32 as a function of the standard deviation of that lottery. The estimates come from three separate logit regressions of choice on one independent variable: the

\footnotetext{
${ }^{17}$ In fact the correlation between period and dexp (stdv) is $0.1733^{* * *}(0.0044)$ respectively (Spearman correlation test).
} 


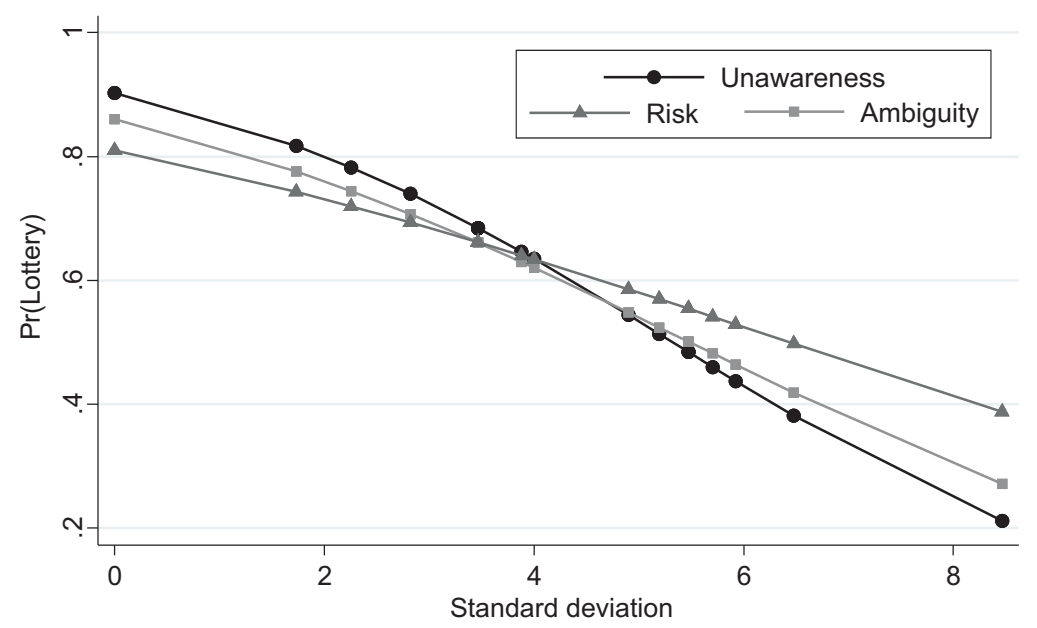

Figure 2: Predicted probabilities (from separate logit regressions) of choosing a lottery as a function of its standard deviation in the three treatments (standard deviation has mean 4.54, see Table 2 for details).

standard deviation of the lottery. As expected, lotteries with higher standard deviation are chosen less often reflecting risk aversion. Most interestingly, though, the order of treatments reverses as standard deviation increases. Lotteries with low standard deviation are chosen most often in the Unawareness treatment and least often in the Risk treatment. For lotteries with high standard deviation this effect is exactly opposite - they are chosen most often in the risk treatment and least often in the Unawareness treatment. Interestingly all three treatments intersect at about the same point. $^{18}$

In terms of the mean-variance criterion $\alpha_{\theta}\left(\mu_{\ell}-x\right)-\beta_{\theta} \sigma_{\ell}$ our results (from Table 3) imply the following ranking of our treatments:

$$
\begin{aligned}
& \alpha_{\text {Unawareness }}=\alpha_{\text {Ambiguity }}=\alpha_{\text {Risk }} \\
& \beta_{\text {Unawareness }}>\beta_{\text {Ambiguity }}>\beta_{\text {Risk}} .
\end{aligned}
$$

In addition Table 3 shows as well that

$$
K_{\text {Unawareness }}>K_{\text {Ambiguity }}>K_{\text {Risk }}
$$

Hence, while the participants' reaction to expected value in all treatments is the same, they react more strongly to variance in the Unawareness treatment than in the Ambiguity treatment than in the Risk treatment. The effect is sizeable. The increase in $\beta$ is $50 \%$ when moving from Risk to Ambiguity and it is even $90 \%$ when moving from Risk to Unawareness. Keep in mind that here we are talking about choices in periods 17 to 32, i.e. about the spillover effect from having experienced choices in a

\footnotetext{
${ }^{18}$ In Appendix B of the Supplementary Material the same figure with error bars (plus minus one standard error) is shown.
} 
risky/ambiguous environment or an environment characterized by unawareness on standard decision making under risk. In Section 5 we show that the effect obtains also when we consider only periods 25 to 32 . In fact the qualitative results are the same as described above and, interestingly, are even more pronounced. This shows that the effect of uncertainty of the environment does not wash out after only a few periods and lasts until the end of the experiment.

Finally, we compare the distributions of individual risk attitudes in periods 17 to 32 in all three treatments. As was mentioned in Section 3 the weight $\beta$ on standard deviation in the mean-variance utility model can be thought of as an estimator of risk attitude. For each participant $i$ in our experiment we ran a logit regression, with which we explain their choices in periods 17 to 32 by the variables dexp and stdv to estimate individual coefficients $\alpha_{i}$ and $\beta_{i}{ }^{19}$ Figure 3 shows the cumulative distributions of $\beta_{i}$ for the three treatments.

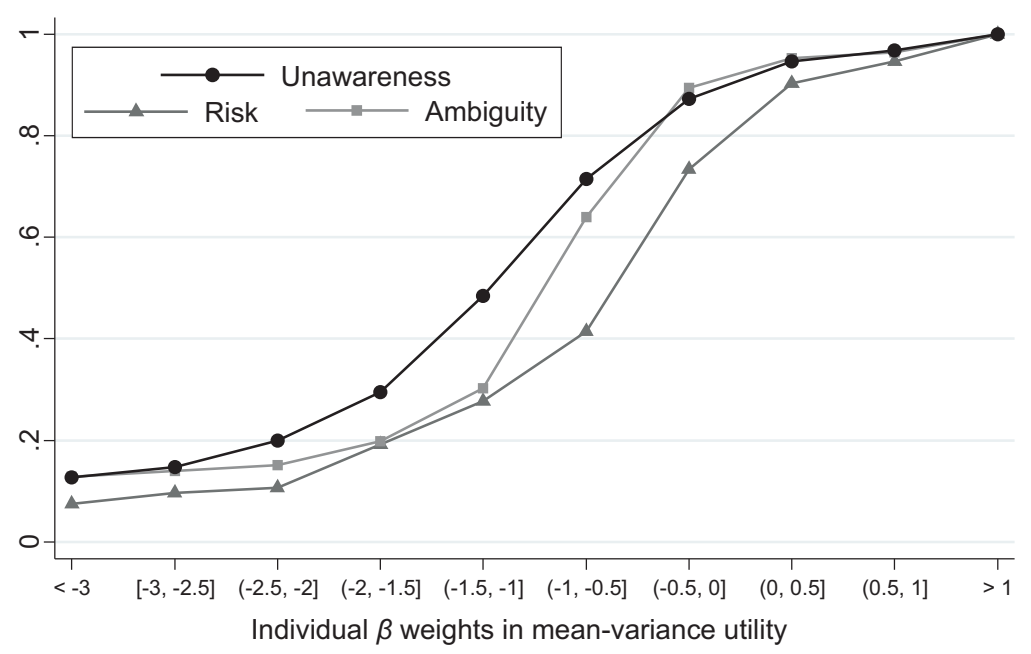

Figure 3: Cumulative distributions of (the negative of) individual $\beta$ weights (risk attitudes) in Risk, Ambiguity and Unawareness treatments.

Notice that the cdf of risk attitudes in Unawareness treatment first-order stochastically dominates cdf in Risk treatment. ${ }^{20}$ The cdf for Ambiguity treatment is in between the cdfs for the Unawareness and Risk treatments in terms of first order stochastic dominance in the steep part of the graph where most observations are. A Kolmogorov-Smirnov test rejects the hypothesis that the distribution of individual $\beta$ 's comes from the same distribution pairwise for any two treatments $(p<0.0001){ }^{21}$

\footnotetext{
${ }^{19}$ We dropped participants who always chose either lottery or sure outcome. This left us with 96 participants in the Unawareness treatment, 87 in ambiguity and 97 in the risk treatment.

${ }^{20}$ The graph plots the distribution of the negative of the risk aversion parameter. Hence indeed the distribution of $\beta^{\prime}$ s in the Unawareness treatment first-order stochastically dominates that of the Risk treatment.

${ }^{21}$ The CRRA estimations reported in Section D of the Supplemental Material show the same patterns: 1) the cdfs for the three treatments are still ranked according to stochastic dominance in the same way; 2 ) the individual CRRA coefficients and $\beta$ coefficients have significantly positive correlation.
} 
Figure 4 reports the distribution of individual $\alpha_{i}$ coefficients. Distributions look very similar across the three treatments (and are not significantly different, $p>0.2$ ) which supports the previous claim that uncertainty of the environments does not affect our participants' attitude towards expectation of the lotteries.

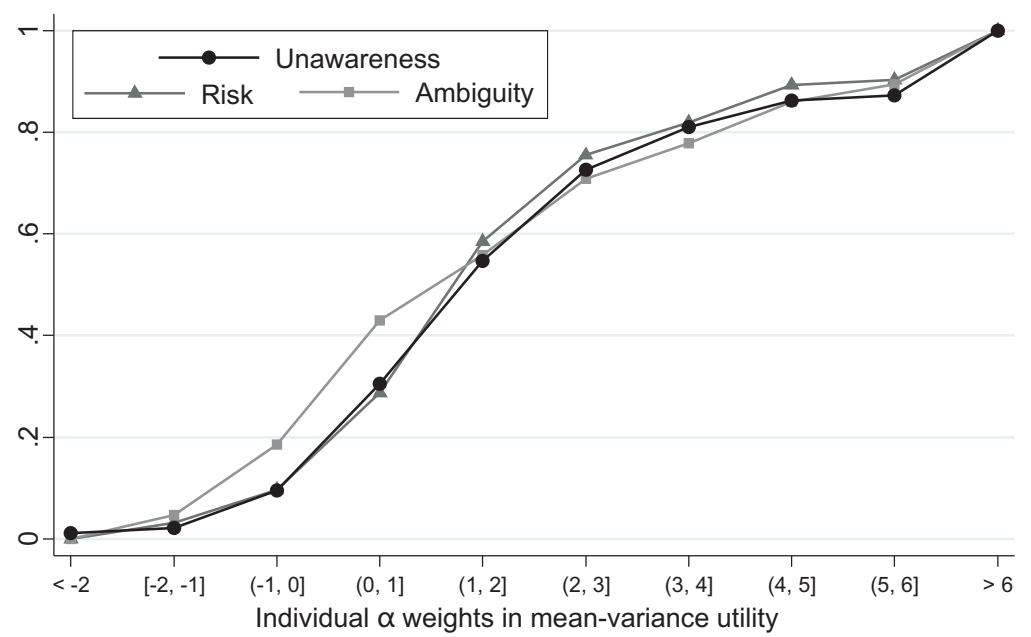

Figure 4: Cumulative distributions of individual $\alpha$ weights in Risk, Ambiguity and Unawareness treatments.

In Section 5 we will discuss our three additional treatments: 1) Unawareness-POS; 2) Risk-high and 3) the Control treatment to rule out different explanations for our main result.

Result 1 1. Participants in the Unawareness treatment are more (less) likely on average to choose low (high) variance lotteries than participants in the Ambiguity treatment than participants in the Risk treatment, implying the following ranking of risk parameters $\beta$ on the population level: $\beta_{\text {Unawareness }}>\beta_{\text {Ambiguity }}>\beta_{\text {Risk. }}$.

2. The distributions of individual risk attitude parameters across the three treatments are ranked as follows in terms of first-order stochastic dominance: $\beta_{\text {Unawareness }} \succ_{\text {FOSD }} \beta_{\text {Ambiguity }} \succ_{\text {FOSD }} \beta_{\text {Risk. }}$.

\section{Discussion and Explanation}

In this section we first show that the treatment effect on risk aversion lasts until the end of the experiment. Then we present evidence from an additional treatment designed to control for the effect of positive vs. negative surprises. Next, we discuss evidence from an additional Risk treatment, where we increased the variance of the lottery in periods 1 to 16 by $300 \%$. Comparing this treatment with our main treatments allows us to clarify to which extent the main result is driven by priors in the Ambiguity and Unawareness treatment that might lead to higher perceived risk in periods 1 to 16 . This treatment also shows how important the effect of imperfect 
knowledge of the state space is in comparison with a pure increase in risk. We then discuss our Control treatment, consisting only of the second task (periods 17 to 32). And finally we analyze behavior differences across treatment in periods 1 to 16 .

\subsection{Is the effect transitory?}

We rerun our main regression (Table 3), but this time we select data only from periods 25 to 32 to see whether the effect is persistent (in our experiment) or whether it vanishes after a few periods. Table 4 reports the results.

\begin{tabular}{|c|c|c|c|c|c|}
\hline \multicolumn{6}{|c|}{$\begin{array}{c}\text { Pr(Lottery) } \\
\text { Risk, Ambiguity, Unawareness }\end{array}$} \\
\hline & (1) & (2) & (3) & (4) & $(5)$ \\
\hline $\operatorname{dexp}$ & $\begin{array}{l}1.255^{* * *} \\
(0.163)\end{array}$ & $\begin{array}{l}1.218^{* * *} \\
(0.154)\end{array}$ & $\begin{array}{l}1.223^{* * *} \\
(0.096)\end{array}$ & $\begin{array}{l}1.114^{* * *} \\
(0.149)\end{array}$ & $\begin{array}{l}1.121^{* * *} \\
(0.089)\end{array}$ \\
\hline stdv & $\begin{array}{c}-0.246^{* * *} \\
(0.091)\end{array}$ & $\begin{array}{l}-0.231^{* * *} \\
(0.089)\end{array}$ & $\begin{array}{c}-0.231^{* * *} \\
(0.089)\end{array}$ & $\begin{array}{c}-0.188^{* *} \\
(0.087)\end{array}$ & $\begin{array}{c}-0.188^{* *} \\
(0.087)\end{array}$ \\
\hline per & $\begin{array}{c}-0.097^{* *} \\
(0.045)\end{array}$ & $\begin{array}{l}-0.072^{* * *} \\
(0.025)\end{array}$ & $\begin{array}{l}-0.073^{* * * *} \\
(0.025)\end{array}$ & & \\
\hline unawar & $\begin{array}{l}1.372 \\
(1.051)\end{array}$ & $\begin{array}{l}2.456^{* * *} \\
(0.639)\end{array}$ & $\begin{array}{l}2.551^{* * * *} \\
(0.611)\end{array}$ & $\begin{array}{l}2.435^{* * * *} \\
(0.638)\end{array}$ & $\begin{array}{l}2.538^{* * *} \\
(0.610)\end{array}$ \\
\hline$a m b$ & $\begin{array}{l}1.383 \\
(1.067)\end{array}$ & $\begin{array}{l}1.298^{* *} \\
(0.641)\end{array}$ & $\begin{array}{l}1.194^{*} \\
(0.611)\end{array}$ & $\begin{array}{l}1.287^{* *} \\
(0.641)\end{array}$ & $\begin{array}{l}1.181^{*} \\
(0.610)\end{array}$ \\
\hline unawar.stdv & $\begin{array}{l}-0.564^{* * *} \\
(0.133)\end{array}$ & $\begin{array}{l}-0.613^{* * *} \\
(0.127)\end{array}$ & $\begin{array}{l}-0.605^{* * *} \\
(0.127)\end{array}$ & $\begin{array}{l}-0.609^{* * * *} \\
(0.127)\end{array}$ & $\begin{array}{l}-0.601^{* * *} \\
(0.126)\end{array}$ \\
\hline$a m b \cdot s t d v$ & $\begin{array}{c}-0.300^{* *} \\
(0.132)\end{array}$ & $\begin{array}{c}-0.295^{* *} \\
(0.126)\end{array}$ & $\begin{array}{c}-0.297^{* *} \\
(0.126)\end{array}$ & $\begin{array}{c}-0.292^{* *} \\
(0.126)\end{array}$ & $\begin{array}{c}-0.294^{* *} \\
(0.126)\end{array}$ \\
\hline unawar.dexp & $\begin{array}{l}0.028 \\
(0.230)\end{array}$ & $\begin{array}{l}0.135 \\
(0.214)\end{array}$ & & $\begin{array}{l}0.143 \\
(0.214)\end{array}$ & \\
\hline amb·dexp & $\begin{array}{r}-0.110 \\
(0.230)\end{array}$ & $\begin{array}{r}-0.118 \\
(0.210)\end{array}$ & & $\begin{array}{r}-0.118 \\
(0.210)\end{array}$ & \\
\hline unawar.per & $\begin{array}{l}0.078 \\
(0.060)\end{array}$ & & & & \\
\hline amb.per & $\begin{array}{r}-0.005 \\
(0.061)\end{array}$ & & & & \\
\hline const & $\begin{array}{l}1.500^{* *} \\
(0.740)\end{array}$ & $\begin{array}{l}1.161^{* *} \\
(0.564)\end{array}$ & $\begin{array}{l}1.162^{* *} \\
(0.551)\end{array}$ & $\begin{array}{l}0.168 \\
(0.448)\end{array}$ & $\begin{array}{l}0.161 \\
(0.431)\end{array}$ \\
\hline$N$ & 310 & 310 & 310 & 310 & 310 \\
\hline
\end{tabular}

Table 4: Random effects logit regression of choices between lotteries and sure outcomes in periods 25 to 32 in Risk, Ambiguity and Unawareness treatments ${ }^{*}-10 \%$ significance; $^{* *}-5 \%{ }^{* * *}-1 \%$ ). 2480 observations, 310 independent.

As in Table 3 the sensitivity to standard deviation is lowest in the Risk treatment (stdv), higher in the Ambiguity treatment (stdv + amb·stdv), and highest in the Unawareness treatment (stdv + unawar.stdv). In the Ambiguity treatment the regression coefficient for the standard deviation of the lottery is -0.528 with standard error 0.093 and $p<0.0001$. In the Unawareness treatment it is -0.836 with standard error 0.093 and $p<0.0001$ (column 3). The difference of coefficients between Unawareness and Ambiguity treatments is -0.308 with standard error 0.128 and $p<0.017$ (unawar.stdv - amb·stdv). Again there are no treatment differences with respect to 
the variable dexp nor with respect to period. This is remarkably similar to our earlier results and shows that the effect is unfading and-if at all-even becomes stronger.

Result 2 Treatment differences in estimated risk aversion found in Result 1 persist throughout the experiment. In periods 25 to 32 treatment differences are even stronger than in periods 17 to 32.

\subsection{Surprise vs. Exposure to Positive or Negative Events}

One may conjecture that it is the negativity of surprise rather than surprise per se that triggers our results. Such an explanation based on negative surprise could at least explain the ranking between the Risk and the Unawareness treatment. It cannot explain, though, the difference between the Ambiguity and the Risk treatment. The reason is that surprises should be "positive" in the Ambiguity treatment (when participants realize that negative outcomes occur with very low probability as very few subjects observe them at all).

To collect additional evidence against this explanation we conducted an additional treatment. Unawareness-POS is the same as the Unawareness treatment but with +20 instead of the -20 outcome. ${ }^{22}$ Table 5 shows the results of a regression comparing the Risk, the Ambiguity and the Unawareness-POS treatments. Participants in the Unawareness-POS treatment tend to choose lotteries with low variance significantly more often than participants in the Risk treatment. For lotteries with high standard deviation this effect reverses. They are chosen most often by participants in the Risk treatment, followed by the Ambiguity treatment and least often by participants in the Unawareness-POS treatment. Qualitatively these results and the implied treatment rankings are exactly the same as those obtained with the original Unawareness treatment with negative surprises in Table 3. Figures 5.a and 5.b illustrate the model predictions and individual $\beta_{i}$ coefficients for Unawareness-POS treatment in comparison with three main treatments.

Result 3 Whether surprises are "positive" or "negative" does not affect the ranking of our treatments. In particular $\beta_{\text {Unawareness-POS }}>\beta_{\text {Ambiguity }}>\beta_{\text {Risk. }}$

\subsection{Increase in Risk}

Another possible explanation of the effect of exposure to different levels of uncertainty on the future choices is that subjects perceive a lottery in the Ambiguity and

\footnotetext{
${ }^{22}$ One may wonder why we didn't control for the number of "bad" or "good" outcomes a participant experienced in our main regressions. The reason is that this is endogenous to the degree of risk aversion of participants.
} 


\begin{tabular}{lc}
\hline \hline \multicolumn{2}{c}{ Pr(Lottery) } \\
Risk, Ambiguity, Unawareness-POS \\
\hline dexp & $1.204^{* * *}$ \\
& $(0.104)$ \\
stdv & $-0.308^{* * *}$ \\
& $(0.037)$ \\
unawarpos & $0.909^{* * *}$ \\
& $(0.346)$ \\
amb & $0.613^{*}$ \\
& $(0.333)$ \\
unawarpos·stdv & $-0.190^{* * *}$ \\
& $(0.056)$ \\
amb·stdv & $-0.148^{* * *}$ \\
& $(0.054)$ \\
unawarpos·dexp & -0.165 \\
& $(0.152)$ \\
amb·dexp & -0.105 \\
& $(0.148)$ \\
const & $1.294^{* * *}$ \\
& $(0.269)$ \\
$N$ & 289 \\
\hline \hline
\end{tabular}

Table 5: Random effects logit regression of choices between lotteries and sure outcomes in periods 17 to 32 if surprise in the Unawareness treatment is positive $\left(^{*}-\right.$ $10 \%$ significance; $\left.{ }^{* *}-5 \% ;^{* * *}-1 \%\right)$. The numbers in parentheses are standard errors. 4624 observations, 289 independent.

Unawareness treatments as exhibiting higher variance than the same lottery with observed probabilities. One hypothesis is, hence, that it is only the perceived amount of risk that matters and not the type of uncertainty that participants face. According to this idea the higher is the perceived variance in first 16 periods the more risk averse subjects should become in last 16 periods. If this hypothesis were true a reasonable implication would be that we should have observed the smallest risk aversion in Risk treatment, more risk aversion in the Unawareness treatment and even more risk aversion in the Ambiguity treatment. The perceived variance in the Ambiguity treatment should be highest because subjects observe all possible outcomes and therefore
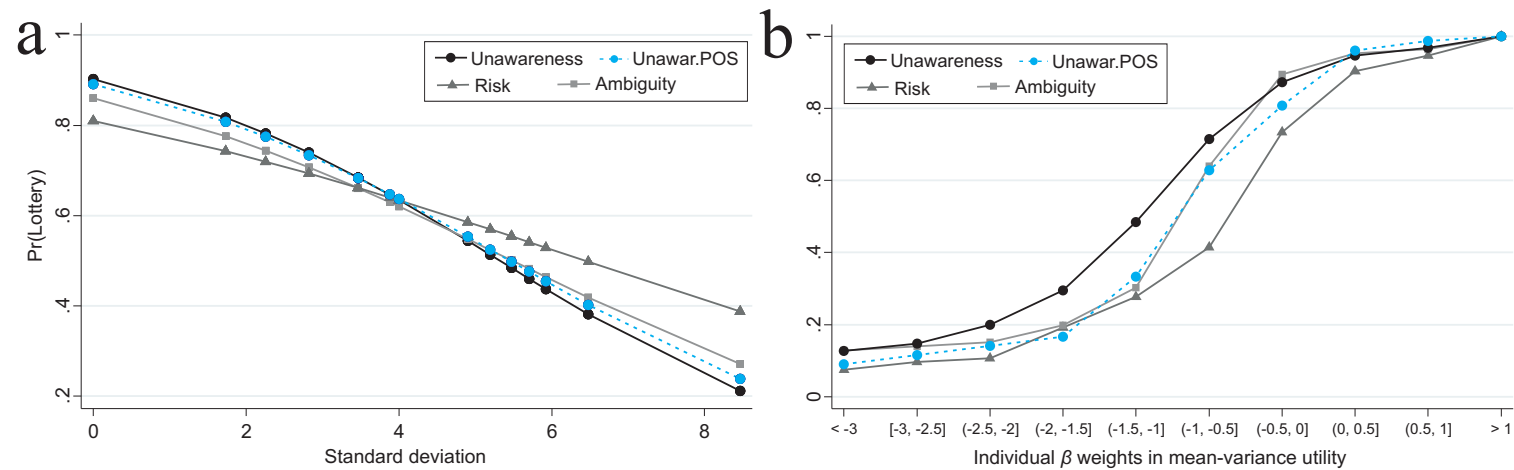

Figure 5: a) Estimated probability to choose a lottery as a function of its standard deviation. Treatments: Risk, Ambiguity, Unawareness and Unawareness-POS; b) Cumulative distributions of individual risk aversion coefficients $\beta_{i}$. Treatments: Risk, Ambiguity, Unawareness, Unawareness-POS. 
might assign high probabilities to negative outcomes, whereas in the Unawareness treatment subjects learn about the existence of negative outcomes only closer to the end of the first 16 periods.

Our analysis refutes this ranking of risk aversion among treatments (see Section 4). In addition, if participants did indeed perceive more risk in the Ambiguity treatment then we should have observed subjects choosing the sure outcome in the Ambiguity treatment substantially more often than in other treatments as the expectation of the lottery with high probabilities on negative outcomes is lower than the original expectation. Again, our data refute this: subjects choose the lottery in the Ambiguity treatment no less often than in other treatments.

In order to collect even more evidence on this issue we ran a Risk treatment with high variance (Risk-high). This treatment is the same as the Risk treatment (all information in first 16 periods is observed), except for the probabilities assigned to the outcomes. Table 6 shows the lottery that participants observe in the Risk-high treatment. The variance of this new lottery is three times higher than that of the original lottery.

\begin{tabular}{llllllll}
\hline Outcomes (Euro) & & & & & & & \\
& -20 & -1 & Twix & 6 & 8 & 10 & 14 \\
& 0.03 & 0.05 & 0.05 & 0.12 & 0.2 & 0.37 & 0.18 \\
Probabilities & & & & & & &
\end{tabular}

Table 6: The lottery from the first 16 choices in Risk with high variance treatment.

Comparing the Risk-high treatment with our main treatments can also help to assess how high an increase in risk should be to match the effect of the ambiguous environment or the environment with unawareness. The regression in Table 7 shows estimates of coefficients in the random effects logit model of choices for all treatments (except the Control treatment). None of the independent variables associated with the Risk-high treatment are significant (riskhigh, riskhigh·dexp, riskhigh·stdv). Choices in the Risk-high treatment are not significantly different from the original Risk treatment.

Figure 6 shows the results graphically. This analysis makes us confident that the effect we observe is not primarily driven by the perceived risk of the lottery, but instead is directly due to the informational environment.

Result $4 \quad$ A 300\% increase in variance produces no change in periods 17 to 32 compared to the Risk treatment. In particular $\beta_{\text {Unawar }}>\beta_{\text {Ambiguity }}>\beta_{\text {Risk }}=$ $\beta_{\text {Risk-High }}$ 


\begin{tabular}{|c|c|}
\hline \multicolumn{2}{|c|}{$\begin{array}{l}\text { Pr(Lottery) } \\
\text { All Treatments }\end{array}$} \\
\hline $\operatorname{dexp}$ & $\begin{array}{l}1.205^{* * *} \\
(0.104)\end{array}$ \\
\hline stdv & $\begin{array}{c}-0.309^{* * * *} \\
(0.037)\end{array}$ \\
\hline unawar & $\begin{array}{l}1.060^{* * *} \\
(0.331)\end{array}$ \\
\hline unawarpos & $\begin{array}{l}0.910^{* * *} \\
(0.347)\end{array}$ \\
\hline$a m b$ & $\begin{array}{l}0.614^{*} \\
(0.333)\end{array}$ \\
\hline riskhigh & $\begin{array}{l}0.407 \\
(0.349)\end{array}$ \\
\hline unawar.stdv & $\begin{array}{c}-0.260^{* * * *} \\
(0.055)\end{array}$ \\
\hline unawarpos $\cdot$ stdv & $\begin{array}{c}-0.190^{* * * *} \\
(0.056)\end{array}$ \\
\hline$a m b \cdot s t d v$ & $\begin{array}{c}-0.148^{* * *} \\
(0.054)\end{array}$ \\
\hline riskhigh.stdv & $\begin{array}{r}-0.016 \\
(0.055)\end{array}$ \\
\hline unawar.dexp & $\begin{array}{r}-0.132 \\
(0.147)\end{array}$ \\
\hline unawarpos·dexp & $\begin{array}{r}-0.165 \\
(0.152)\end{array}$ \\
\hline$a m b \cdot \operatorname{dexp}$ & $\begin{array}{r}-0.105 \\
(0.148)\end{array}$ \\
\hline riskhigh·dexp & $\begin{array}{r}-0.249 \\
(0.154)\end{array}$ \\
\hline const & $\begin{array}{l}0.786^{* * * *} \\
(0.231)\end{array}$ \\
\hline$N$ & 476 \\
\hline
\end{tabular}

Table 7: Random effects logit regression of choices between lotteries and sure outcomes in periods 17 to 32 including all treatments except for the Control treatment $*^{*}-10 \%$ significance; $\left.{ }^{* *}-5 \% ;{ }^{* *}-1 \%\right)$. The numbers in parentheses are standard errors. 7616 observations, 476 independent.

\subsection{Control Treatment}

In this subsection we discuss our control treatment. In the control treatment participants only made the choices from periods 17 to 32 .

The regression in Table 8 shows that participants in the Control treatment behave in the same way as in Risk treatment. There are no significant differences between the two treatments. This is relevant because one may conjecture that some of the observed differences are due to the fact that in the Risk treatment participants, being given more information, have better opportunities to learn to make good choices. Under this explanation we should observe the following treatment ranking: $\beta_{\text {Control }}>\beta_{\text {Unawareness }}>\beta_{\text {Ambiguity }}>\beta_{\text {Risk, }}$ since in the Control treatment there are no opportunities for learning at all. This explanation can be ruled out, since the Risk and Control treatments are not significantly different. Figure 7 shows the distributions of individual $\beta_{i}$ coefficients for the main treatments and the Control treatment. The Control treatment distribution is not very different from that of the Risk treatment. One should be careful to note that we are not claiming that differential learning across 

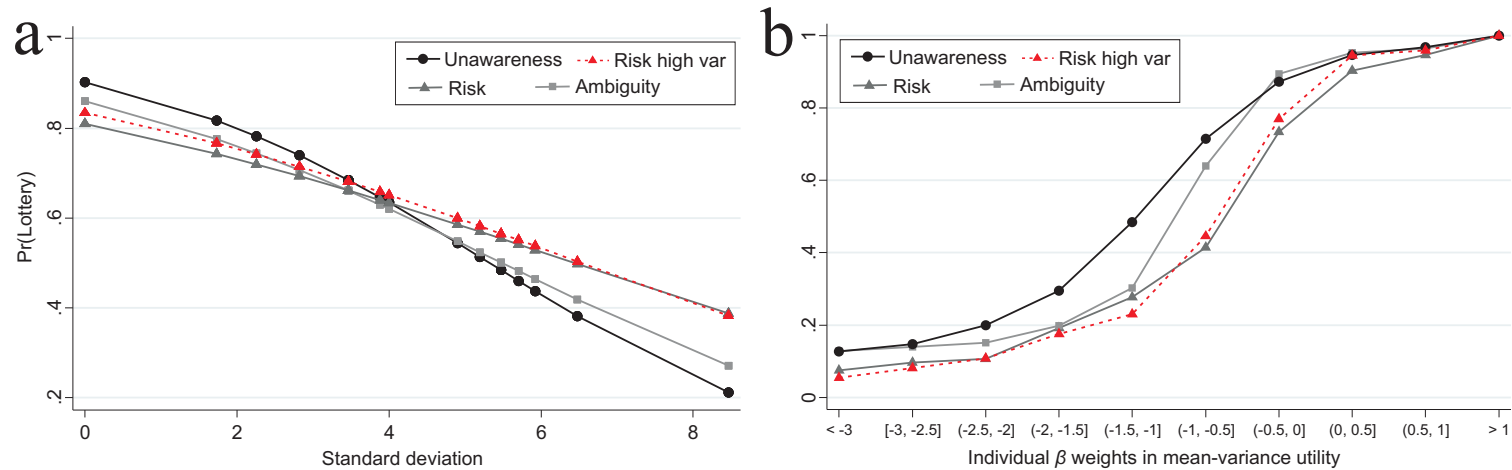

Figure 6: a) Estimated probability of choosing a lottery as a function of its standard deviation. Treatments: Risk, Risk-high, Ambiguity and Unawareness; b) Cumulative distributions of individual risk aversion coefficients $\beta_{i}$. Treatments: Risk, Risk-high, Ambiguity and Unawareness.

\begin{tabular}{lc}
\hline \hline \multicolumn{2}{c}{ Pr(Lottery) } \\
Risk, Control \\
\hline dexp & $1.185^{* * *}$ \\
& $(0.104)$ \\
stdv & $-0.304^{* * *}$ \\
& $(0.037)$ \\
control & 0.108 \\
& $(0.571)$ \\
control·dexp & -0.406 \\
& $(0.249)$ \\
control·stdv & -0.048 \\
& $(0.094)$ \\
const & $0.772^{* * *}$ \\
& $(0.224)$ \\
$N$ & 121 \\
\hline \hline
\end{tabular}

Table 8: Random effects logit regression of choices between lotteries and sure outcomes in periods 17 to 32 in Risk and Control treatments $\left(^{*}-10 \%\right.$ significance; ${ }^{* *}$ $5 \% ;{ }^{* *}-1 \%$ ). The numbers in parentheses are standard errors. 3600 observations, 121 independent.

the three treatments cannot affect behavior. However, we can rule out that the result is primarily due to the fact that participants have less opportunities for learning in the Ambiguity and Unawareness treatments, because they have less information about the lottery.

Result 5 Behavior in the Control treatment is the same as in the Risk treatment in periods 17 to 32. In particular $\beta_{\text {Unawareness }}>\beta_{\text {Ambiguity }}>\beta_{\text {Risk }}=\beta_{\text {Control }}$.

One may ask whether participants carry over different heuristics from periods 1 to 16 to periods 17 to 32 in the three treatments. This is related to a literature on behavioral spillovers (see e.g. Gneezy et al., 2010) concerned with extrapolation of cognitive skills (such as applying backward induction) across games. It is hard to argue that the spillover effects in our experiment have much to do with transfer of cognitive skills or learning, since behavior in the control treatment is not significantly 


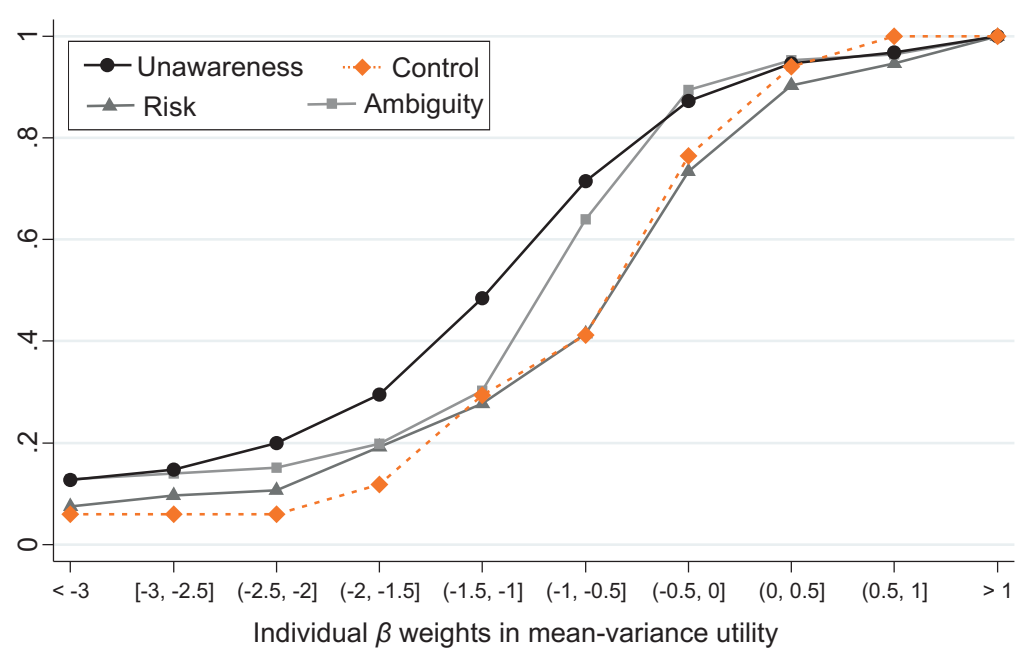

Figure 7: Cumulative distributions of individual risk aversion coefficients $\beta_{i}$. Treatments: Risk, Ambiguity, Unawareness and Control.

different from behavior in the risk treatment. There is also no evidence in our study that participants would use different heuristics in periods 17 to 32 across the different treatments (see Section C in the Supplementary Material). ${ }^{23}$ We also ran regressions on response times in periods 17 to 32 including variables dexp, standev as well as treatment dummies and interactions and we find that all treatment dummies and interactions are jointly insignificant $\left(\mathrm{Pr}>\chi^{2}=0.6688\right)$. This is in stark contrast to periods 1 to 16 (see below). Hence nothing in our evidence suggests that participants would use different heuristics in periods 17 to 32. Instead it seems that their attention is shifted towards giving greater weight to the uncertainty of a choice option.

\subsection{Treatment Comparison in Periods 1 to 16}

Finally we look at treatment comparisons in periods 1 to 16 . We analyze choices of participants in the first 16 periods across all three treatments. Table 9 reports the results of a logit regression of choices on the value of the sure outcome, treatment dummies as well as interaction terms. Note that, since the lottery is the same in periods 1 to 16, there is no point in including variables dexp and stdv.

An important observation is that there are no apparent differences between the Risk and Ambiguity treatments (amb and amb-sure are insignificant). Hence, priors in the Ambiguity treatment do not seem to have been too far from actual probabilities, which are observed in the Risk treatment. They should be at least close enough to produce (statistically) the same behavior. Choices in the Unawareness treatment are different. Here participants seem to be less sensitive to the value of the sure outcome than in the Risk treatment (sure + unawar-sure). Moreover, participants tend

\footnotetext{
${ }^{23}$ Supplementary Material can be found at http://www.vostroknutov.com/pdfs/awarexp04supp.pdf.
} 


\begin{tabular}{lcc}
\hline \hline \multicolumn{3}{c}{ Pr(lottery) } \\
\multicolumn{4}{c}{ Risk, Ambiguity, Unawareness } \\
& $\beta /(s e)$ & $\beta /(s e)$ \\
\hline sure & $-2.025^{* * *}$ & $-2.104^{* * *}$ \\
& $(0.113)$ & $(0.088)$ \\
unawar & $-6.294^{* * *}$ & $-5.748^{* * *}$ \\
& $(0.996)$ & $(0.840)$ \\
amb & -0.761 & \\
& $(1.161)$ & \\
unawar·sure & $0.979^{* * *}$ & $1.051^{* * *}$ \\
& $(0.134)$ & $(0.114)$ \\
amb·sure & -0.203 & \\
& $(0.164)$ & \\
const & $14.312^{* * *}$ & $13.821^{* * *}$ \\
& $(0.826)$ & $(0.621)$ \\
$N$ & 310 & 310 \\
\hline \hline
\end{tabular}

Table 9: Random effects logit regression of choices in the first 16 periods of Risk, Ambiguity and Unawareness treatments.

to choose the sure outcome more often overall (unawar). This is at least consistent with the fact that participants were "unaware" of the hidden outcome in this treatment.

As an additional consistency test we compare a measure of individual risk attitudes in the first 16 periods of the Risk treatment with the individual $\beta_{i}$ coefficients for the last 16 periods discussed in Section 4 . Since the lottery in the first 16 periods is always the same it is not obvious how to measure risk attitudes. Therefore, we use a simple crude measure of risk attitude: the number of times $t_{i}$ each participant chose the lottery. We find that Spearman's rank correlation between $t_{i}$ and $\beta_{i}$ is $\rho=0.18$ with $p<0.09$. In addition, simple OLS regression of $\beta_{i}$ on $t_{i}$ gives significantly positive coefficient $(p<0.046$ ). This tells us that the risk attitudes of participants in Risk treatment are consistent between the first and the second parts of the experiment. ${ }^{24}$

To gain more insight into the nature of the decision process in the first 16 periods we look at the response times across treatments. Table 10 shows that in the Risk and Ambiguity treatments the response time is shorter the higher the sure outcome is. However, in the Unawareness treatment the response time does not react to the value of the sure outcome (sure + unawar.sure is insignificant). Moreover, in the Unawareness treatment there is an overall drop in the response time as compared to the Risk and Ambiguity treatments (unawar). This shows that different reasoning might be used by the participants when choosing in the unawareness environment as compared to ambiguity and risk.

Result 6 1. In the Unawareness treatment participants are less likely to choose the lottery in periods 1 to 16 and react less to the value of the sure outcome compared to

\footnotetext{
${ }^{24}$ The tests reported here were extremely sensitive to outliers in $\beta_{i}$ 's. Hence, observations with $\left|\beta_{i}\right|>6$ were omitted.
} 


\begin{tabular}{|c|c|c|}
\hline \multicolumn{3}{|c|}{$\begin{array}{c}\text { Response time } \\
\text { Risk, Ambiguity, Unawareness }\end{array}$} \\
\hline & $\beta /(s e)$ & $\beta /(s e)$ \\
\hline sure & $\begin{array}{c}-0.421^{* * *} \\
(0.135)\end{array}$ & $\begin{array}{c}-0.450^{* * *} \\
(0.101)\end{array}$ \\
\hline per & $\begin{array}{c}-0.807^{* * *} \\
(0.027)\end{array}$ & $\begin{array}{c}-0.810^{* * *} \\
(0.026)\end{array}$ \\
\hline unawar & $\begin{array}{c}-8.875^{* * *} \\
(1.434)\end{array}$ & $\begin{array}{c}-9.110^{* * *} \\
(1.244)\end{array}$ \\
\hline $\mathrm{amb}$ & $\begin{array}{l}0.478 \\
(1.455)\end{array}$ & \\
\hline unawar.sure & $\begin{array}{l}0.446^{* *} \\
(0.189)\end{array}$ & $\begin{array}{l}0.476^{* * *} \\
(0.167)\end{array}$ \\
\hline amb.sure & $\begin{array}{c}-0.655^{* * *} \\
(0.192)\end{array}$ & $\begin{array}{c}-0.596^{* * *} \\
(0.061)\end{array}$ \\
\hline unawar.per & $\begin{array}{l}0.487^{* * *} \\
(0.038)\end{array}$ & $\begin{array}{l}0.489^{* * *} \\
(0.037)\end{array}$ \\
\hline amb·per & $\begin{array}{l}0.243^{* * *} \\
(0.038)\end{array}$ & $\begin{array}{l}0.248^{* * *} \\
(0.036)\end{array}$ \\
\hline const & $\begin{array}{c}18.216^{* * *} \\
(1.019)\end{array}$ & $\begin{array}{c}18.450^{* * *} \\
(0.727)\end{array}$ \\
\hline$N$ & 310 & 310 \\
\hline
\end{tabular}

Table 10: Random effects regression of response times in the first 16 periods of the Risk, Ambiguity and Unawareness treatments.

either the Risk or Ambiguity treatment which are not significantly different.

2. Response times are overall faster in the Unawareness treatment compared to the Risk and Ambiguity treatments. Response times are shorter the higher the value of the sure outcome in both the Risk and Ambiguity treatments, but do not vary with the value of the sure outcome in the Unawareness treatment.

\section{Conclusions}

We studied decision-making under imperfect knowledge of the state space in an experiment and found that it can have prolonged effects on future risk aversion. In particular, we conducted three treatments with lottery choice tasks. All treatments were identical in later periods, but differed in early periods. In the early periods of the Risk treatment there was perfect information about the lottery; in the Ambiguity treatment participants perfectly knew the outcome space but not the associated probabilities; in the Unawareness treatment participants had imperfect knowledge about both outcomes and probabilities. We found that the distribution of risk parameters in the Unawareness treatment dominates that of the Ambiguity treatment which dominates that of the Risk treatment in the sense of first order stochastic dominance. Even a 300\% increase in risk (measured by the variance of the lottery) in the first phase cannot produce the same effect as the Ambiguity or Unawareness treatments. 
These results are of interest for any social scientist concerned with understanding how life experiences under different informational environments shape personality and attitudes towards risk in particular. Different political systems, media and education systems all create different informational environments. ${ }^{25}$ Our results show how such environments can affect risk attitudes and hence entrepreneurship, saving decisions and other decisions involving risk.

Future research should explore the reasons behind this effect, create and test alternative theories that could explain this phenomenon. In the Supplementary Material accompanying this paper we outline one theoretical model that is consistent with our results. ${ }^{26}$ Future research could be aimed at discriminating between this model and possible alternative explanations.

\section{References}

Alesina, A. and N. Fuchs-Schuendeln (2007). Good bye lenin (or not)? the effect of communism on people's preferences. American Economic Review 97(4), 1507-1529.

Andersen, S., G. W. Harrison, M. I. Lau, and E. E. Rutström (2008). Lost in state space: are preferences stable? International Economic Review 49, 1091-1112.

Barseghyan, L., J. Prince, and J. C. Teitelbaum (2011). Are risk preferences stable across contexts? evidence from insurance data. American Economic Review 101, 591631.

Barsky, R. B., M. S. Kimball, F. T. Juster, and M. D. Shapiro (1997). Preference parameters and behavioral heterogeneity: An experimental approach in the health and retirement survey. Quarterly Journal of Economics 112, 537-579.

Becker, G. M., M. H. DeGroot, and J. Marschak (1964). Measuring utility by a singleresponse sequential method. Behavioral science 9(3), 226-232.

Callen, M., M. Isaqzadeh, J. Long, and C. Sprenger (2014). Violence and risk preference: Experimental evidence from Afghanistan. American Economic Review 104(1), 123-148.

Cason, T. and C. Plott (2014). Misconceptions and game form recognition: Challenges to theories of revealed preference and framing. Journal of Political Economy in press.

Dekel, E., B. Lipman, and A. Rustichini (1998). Standard state-space models preclude unawareness. Econometrica 66(1), 159-173.

Dohmen, T., A. Falk, D. Huffman, U. Sunde, J. Schupp, and G. G. Wagner (2011). Individual risk attitudes: measurement, determinants, and behavioral consequences. Journal of the European Economic Association 9(3), 522-550.

\footnotetext{
${ }^{25}$ Alesina and Fuchs-Schuendeln (2007) have shown how experiencing different political systems can affect preferences for redistribution.

${ }^{26}$ Supplementary Material can be found at http://www.vostroknutov.com/pdfs/awarexp04supp.pdf.
} 
Einav, L., A. Finkelstein, I. Pascu, and M. Cullen (2012). How general are risk preferences? choices under uncertainty in different domains. American Economic Review 102(6), 2606-2638.

Ellsberg, D. (1961). Risk, ambiguity, and the savage axioms. Quarterly Journal of Economics 75(4), 643-669.

Fagin, R. and J. Halpern (1988). Belief, awareness, and limited reasoning. Artificial Intelligence 34, 39-76.

Feinberg, Y. (2009, April). Games with unawareness. Stanford University.

Fischbacher, U. (2007, June). z-tree: Zurich toolbox for ready-made economic experiments. Experimental Economics 10(2), 171-178.

Giuliano, P. and A. Spilimbergo (2009). Growing up in a recession: beliefs and the macroeconomy. UCLA, NBER, IZA, IMF, WDI and CEPR.

Gneezy, U., A. Rustichini, and A. Vostroknutov (2010, August). Experience and insight in the race game. Journal of Economic Behavior and Organization 75, 144-155.

Gollier, C. (2011). Portfolio choices and asset prices: The comparative statics of ambiguity aversion. Review of Economic Studies 78(4), 1329-1344.

Gossner, O. and E. Tsakas (2010). A reasoning approach to introspection and unawareness. METEOR Research Memorandum RM/10/006, Maastricht University.

Gossner, O. and E. Tsakas (2012). Reasoning-based introspection. Theory and Decision $73,513-523$.

Halevy, Y. (2007). Ellsberg revisited: An experimental study. Econometrica 75, 503-536.

Halpern, J. Y. and L. C. Rêgo (2008). Interactive unawareness revisited. Games and Economic Behavior 62(1), 232-262.

Halpern, J. Y. and L. C. Rêgo (2009, November). Reasoning about knowledge of unawareness. Games and Economic Behavior 67(2), 503-525.

Heifetz, A., M. Meier, and B. C. Schipper (2006). Interactive unawareness. Journal of Economic Theory 130, 78-94.

Heifetz, A., M. Meier, and B. C. Schipper (2008). A canonical model of interactive unawareness. Games and Economic Behavior 62, 304-324.

Karni, E. and Z. Safra (1987). Preference reversal and the observability of preferences by experimental methods. Econometrica 55(3), 675-685.

Kim, Y.-I. and J. Lee (2014). The long-run impact of a traumatic experience on risk aversion. Journal of Economic Behavior and Organization in press.

Knight, F. (1921). Risk, uncertainty and profit. Boston: Houghton Mifflin.

Levy, H. and H. M. Markowitz (1979). Approximating expected utility by a function of mean and variance. American Economic Review 69, 308-317. 
Li, J. (2009). Information structures with unawareness. Journal of Economic Theory 144, 977-993.

Maccheroni, F., M. Marinacci, and A. Rustichini (2006, November). Ambiguity aversion, robustness, and the variational representation of preferences. Econometrica 74(6), 1447-1498.

Malmendier, U. and S. Nagel (2011). Depression babies: do macroeconomic experiences affect risk taking? Quarterly Journal of Economics 126(1), 373-346.

Markowitz, H. (1952). Portfolio selection. Journal of Finance 7(1), 77-91.

McFadden, D. (1976). Quantal choice analysis: A survey. Annals of Economics and Social Measurement 5, 363-390.

Modica, S. and A. Rustichini (1994). Awareness and partitional information structures. Theory and Decision 37(1), 107-124.

Modica, S. and A. Rustichini (1999). Unawareness and partitional information structures. Games and Economic Behavior 27, 265-298.

Nishiyama, Y. (2006). The asian financial crisis and investors' risk aversion. AsiaPacific Financial Markets 13, 181-205.

Osili, U. O. and A. Paulson (2009). Banking crises and investor confidence: An empirical investigation. Indiana University-Purdue University at Indianapolis and Federal Reserve Bank of Chicago.

Preuschoff, K., P. Bossaerts, and S. R. Quartz (2006). Neural differentiation of expected reward and risk in human subcortical structures. Neuron 51(3), 381-390.

Sharpe, W. (2008). Investors and Markets: Portfolio Choices, Asset Prices and Investment Advice. Princeton University Press.

Starmer, C. and R. Sugden (1991). Does the random-lottery incentive system elicit true preferences? an experimental investigation. American Economic Review 81(4), 971-978. 